\title{
Putzen schadet der Lunge ähnlich wie Rauchen
}

Schlechte Nachrichten für Sauberkeitsfans: Wer regelmäßig Reinigungsmittel benutzt, schadet seiner Lunge so, als ob man jahrelang raucht. Diesen Effekt fanden Forscher aber nur bei Frauen - doch sie haben dafür eine Erklärung.

Die Wohnung sauber zu machen, kann einer Hausstauballergie vorbeugen. Doch regelmäßiges Reinigen kann auch eine schädliche Nebenwirkung haben: Einer Studie der Universität Bergen, Norwegen, nach, sind Frauen, die regelmäßig putzen oder beruflich reinigen, langfristig öfter von einem starken Abfall der Lungenfunktion betroffen. Die Daten wurden im American Journal of Respiratory and Critical Care Medicine veröffentlicht [1].

Verglichen mit Frauen, die nicht putzten, fiel der Leistungsabfall beim Forced expiratory volume (FEV1) pro Jahr bei Frauen, die zu Hause sauber machten (FEV1 $=-22,1 \mathrm{ml}$ versus $-18,5 \mathrm{ml}$, $p=0,01)$, höher aus. Professionelle Reinigungskräfte erlitten sogar einen noch höheren Leistungseinbruch der Lunge $(-22,4 \mathrm{ml}, p=0,03)(\bullet$ Abb. 1$)$.

Dieses Ergebnis bestätigte sich auch bei der Forced vital capacity (FVC): Ohne Putztätigkeit betrug der Einbruch $8,8 \mathrm{ml}$ pro Jahr, Hobby-Putzer litten un-

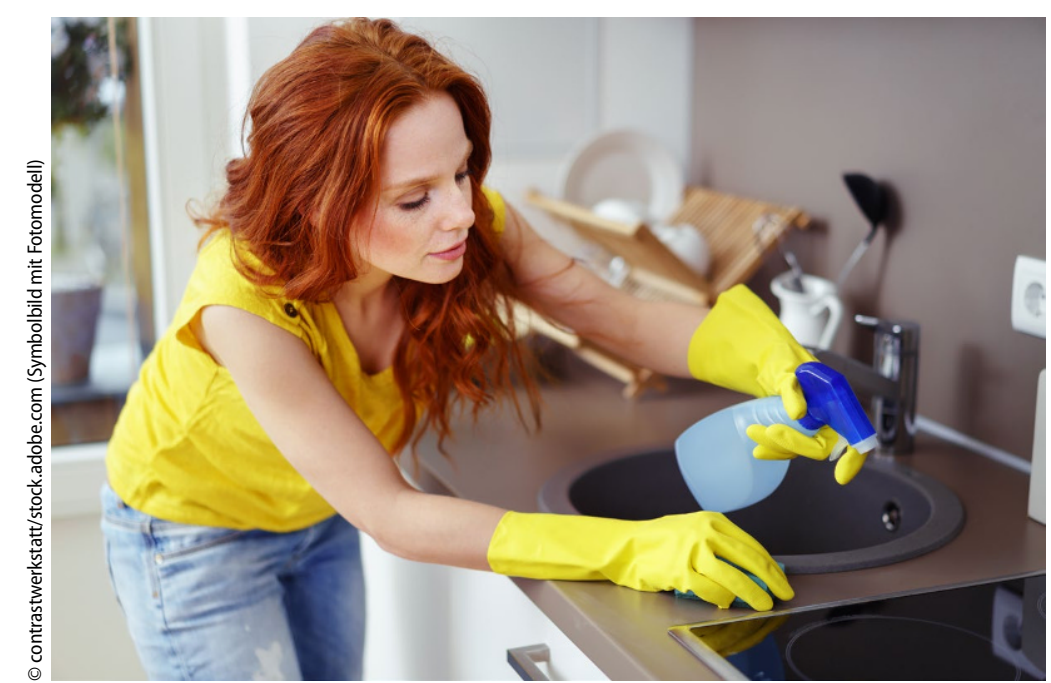

Abb. $1 \Delta$ Frauen, die beruflich reinigen, sind öfter von einem starken Abfall der Lungenfunktion betroffen

ter einem Abfall von 13,1 $\mathrm{ml}(p=0,02)$ und Profi-Reinigungskräfte von $15,9 \mathrm{ml}$ $(p=0,02)$.

\section{Warum nur bei Frauen?}

„Der Effekt, den professionelles Reinigen auf die Lunge hat, war so, als ob eine Person rund 20 Packungsjahre geraucht hat", beschreiben die Autoren die Auswirkungen in der Studie. Bei Männern fanden sie dagegen keinen Unterschied zwischen regelmäßigen Putzern und Putzmuffeln - weder bei FEV1 noch bei FVC.

Das lag, den Forschern zufolge, wohl aber schlicht daran, dass sie nur 57 professionelle männliche Reinigungskräfte in der Datenbank hatten. Möglicherweise könnte der Auswirkungsunterschied aber auch daran liegen, dass Frauen schon bei geringerer Exposition mit Lungen-Schadstoffen stärker reagierten - so das Ergebnis anderer Studien (z.B. die von Silverman oder Foreman). 